\title{
Evaluation of Sperm Motility with Glutathione and Honey in Skim Milk based Extenders by CASA in Boer Buck
}

\author{
Suresh Arakeri ${ }^{1 *}$, M. K. Tandle ${ }^{2}$, M. D. Suranagi ${ }^{2}$, Vinay Tikare ${ }^{2}$, R. G. Bijurkar ${ }^{2}$, \\ Jagannath Rao $^{2}$ and Shrikant Kulkarni ${ }^{2}$ \\ ${ }^{1}$ Veterinary Officer, Dharwad, Karnataka, India \\ ${ }^{2}$ KVAFSU, Bidar, Karnataka, INDIA \\ *Corresponding author
}

\section{A B S T R A C T}

\section{Keywords}

Glutathione, Honey, Skim milk, Buck, Sperm, CASA

\section{Article Info}

Accepted: 28 April 2020 Available Online: 10 May 2020
The aim of the study was to evaluate and compare Boer buck sperm motility with $5 \mathrm{mM}$ Glutathione $(\mathrm{G})$ and or $1 \%$ or $2 \%$ Honey $(\mathrm{H})$ in Skim milk $(\mathrm{SM})$ based extenders preserved at refrigeration temperature at $0,24,48$ and $72 \mathrm{hrs}$. A total of 72 ejaculates were collected equally from 6 mature bucks at weekly interval by using Artificial Vagina (AV) as per standard procedure. All the ejaculates were diluted using six Skim milk based extenders viz. SME, SMGE, SMGH(1\%)E, $\operatorname{SMGH}(2 \%) \mathrm{E}, \mathrm{SMH}(1 \%) \mathrm{E}$ and $\mathrm{SMH}(2 \%) \mathrm{E}$. The sperm motility was evaluated by CASA (Computer Assisted Semen Analyzer). The data obtained was statistically analyzed by General Linear Model (GLM) and procedure. The results showed that sperm motility was differed significantly $(\mathrm{P}<0.05)$ from extender to extender at 24 $\mathrm{h}, 48 \mathrm{~h}$ and $72 \mathrm{~h}$ of refrigeration. Based on the results concluded that supplementation of optimum concentration of glutathione $(5 \mathrm{mM})$ and honey $(1 \%)$ maintained better sperm motility upto 72 hours of storage and successful preservation of buck spermatozoa at refrigeration temperature. Hence study revealed that Boer buck semen can be preserved effectively with $\mathrm{SMGH}(1 \%) \mathrm{E}$, at refrigeration temperature upto 72 hours of storage.

\section{Introduction}

Five home-made Skim-milk extenders like cow skim-milk (CSM), goat skim-milk (GSM), sheep skim-milk (SSM), buffalo skim-milk (BSM) and commercial dried skim-milk (CDSM) were examined for the motility, morphology, plasma membrane integrity and viability of sperms at $0,24,48$, 72, 96 and 120 hours respectively (Rimon et al., 2017). Removal of seminal plasma improved the viability and longevity of Beetal buck spermatozoa in skimmed milk based extenders during cooling upto 72 hours (Hassan et al., 2016).

Generally sperm motility is expressed in terms of mass motility and progressive motility. Conventional methods for measuring the sperm kinematic characters is difficult, time consuming and subjective. To get over these difficulties Computer Assisted Semen 
Analysis (CASA) is the equipment of choice to provide precise and accurate information on sperm motion characteristics. The importance of analyzing kinematics and motility patterns of spermatozoa were studied using CASA (Anand et al., 2016).

The sperm motility, viability and fertilizing ability can be improved or preserved by the addition of various motility enhancing agents or antioxidants in semen diluents. These antioxidants can neutralize or reduce the risk of damage to spermatozoa by activating antioxidant enzymes (Glutathione peroxidase - GSH and Catalase) during cryopreservation process or combating harmful effects of ROS. Glutathione plays a cofactor role for glutathione peroxidase (GSH) which in turn reduces hydrogen peroxide $\left(\mathrm{H}_{2} \mathrm{O}_{2}\right)$ to $\mathrm{H}_{2} \mathrm{O}$ and also lipoperoxides to alkyl alcohols (Noei et al., 2015). Glutathione and Vitamin-E improved the buck seminal parameters during hypothermic storage of liquid semen at $4^{0} \mathrm{C}$ for 72 hours (Sarangi et al., 2017). Honey bee (HB) has a potent antioxidant and antibacterial properties (Zoheir et al., 2015). At low temperatures honey does not freeze and its viscosity increases with decreasing the temperature. This creates a low surface tension that eventually minimizes the formation of ice crystals inside the cytoplasm of sperm and hence reduces damage to the spermatozoa during cryopreservation (ElSheshtawy et al., 2014).

Years to come with supplementation of an agent in the extender that can overcome the threat of antibiotic resistance and at the same time would maintain the motility of sperm by taking care of heavy bacterial load in the buck's semen to prove a very useful strategy for successful preservation (Banday et al., 2017). The wide property of honey and its addition into freezing medium is also expected for the protection of spermatozoa during cryopreservation. To this honey as a natural product and has been studied as supplement with different properties like synergistic antioxidant, non-permeant cryoprotectant and energy source for the improvement of post-thaw semen quality (Yimer et al., 2015).

\section{Materials and Methods}

The study was carried out in six sexually mature Boer bucks maintained at Department of Veterinary Gynaecology and Obstetrics, Veterinary College, Bidar. All the bucks were maintained under uniform conditions and reared under semi-intensive housing system. Bucks were kept in a single flock with routine deworming and vaccination as per schedule. The bucks were allowed for free grazing for 5-6 hrs daily, fed concentrate @ 250 g per day per animal and provided ad libitum drinking water throughout the day.

\section{Preparation of honey solution}

$1 \mathrm{~mL}$ of honey was added to $9 \mathrm{~mL}$ double distilled water $(\mathrm{v} / \mathrm{v})$ to prepare a total concentration of $10 \%(10 \mathrm{ml})$ honey solution (El-Sheshtawy et al., 2014). Out of $10 \mathrm{ml}$ $(10 \%, \mathrm{v} / \mathrm{v})$ honey solution the volume of $1 \mathrm{ml}$ and $2 \mathrm{ml}$ having of $1 \%(\mathrm{v} / \mathrm{v})$ and $2 \%(\mathrm{v} / \mathrm{v})$ concentrations respectively were used.

\section{Semen collection}

A total of 72 ejaculates were collected equally from 6 mature bucks at weekly interval by using Artificial Vagina (Fig. 1) as per standard procedure.

\section{Mass activity}

A drop $(0.5 \mu \mathrm{L})$ of neat semen was placed on a pre-warmed glass slide $\left(37^{\circ} \mathrm{C}\right)$ without cover slip and examined under phase contrast microscope $(100 \quad \mathrm{X})$ with low power magnification $(100 \mathrm{X})$. Wave motion 
characteristics or swirl motion of the spermatozoa were scored (Table 1) from + to ++++ scale (Blokhuis, 1962).

\section{Sperm motility}

It was assessed using a phase contrast microscope (400 $\mathrm{X}$ magnification) with a warm stage maintained at $37^{\circ} \mathrm{C}$. A wet semen mount was made using a small drop of semen placed directly on a microscope slide covered by a cover slip (Loskutoff and Crichton, 2001) and sperm motility was scored (Table 2).

\section{Semen dilution}

The collected ejaculates were centrifuged @ $1,500 \mathrm{rpm}$ for 10 minutes and supernatant seminal plasma was discarded. The sperm pellets (Fig. 2) washed with isosmotic phosphate buffered saline (PBS) solution in equal volume to obtain an optimal concentration and $\mathrm{pH}$ for the sample. Then buck wise sperm pellet sample was diluted with 6 (Table 3) different extenders (1:60) stored at refrigeration temperature and thawed to room temperature $\left(37^{\circ} \mathrm{C}\right)$ in a water bath at the time of semen evaluation.

\section{Evaluation of semen by computer assisted semen analysis (CASA)}

All the diluted sperm pellet samples were preserved at refrigeration temperature and thawed to room temperature $\left(37^{\circ} \mathrm{C}\right)$ in a water bath at the time of evaluation by Computer Assisted Semen Analysis system using model Biovis - CASA 2000 (Expert Vision labs Pvt. Ltd. Mumbai, India) at 0, 24, 48 and 72 hours of storage.

\section{CASA procedure}

A drop of diluted semen was taken on a clean grease free slide which was covered by a cover slip and it was focussed under phase contrast microscope with 100 X magnification. Biovis-CASA software was turned on, fine adjustment was made for viability and clicked on option capture which captured around 60 frames/minute then automatically analysed for sperm concentration, motility and other mentioned parameters (Fig. 3). Assessment of diluted chilled semen by CASA was performed at 24 , 48 and $72 \mathrm{~h}$ of storage.

\section{Statistical analysis}

The data obtained was statistically analyzed by General Linear Model (GLM) and procedure using SAS - Statistics Version 9.3, SAS Inc., Cary, NC; 2010 software.

\section{Results and Discussion}

\section{Semen evaluation tests in Boer bucks}

The volume of neat semen ranged from 0.81 to $1.30 \mathrm{ml}$ having whitish yellow color. The mass activity was ++++ scale for all semen samples and sperm motility ranged from $91.66 \pm 1.12 \%$ to $96.66 \pm 1.42 \%$ and none of the samples has shown presence of any foreign body (Table 4 and Figure 1).

Comparative effect of Boer buck sperm motility with $5 \mathrm{mM}$ glutathione and or $1 \%$ or $2 \%$ honey in skim milk based extenders preserved at refrigeration temperature at $0,24,48$ and $72 \mathrm{~h}$

\section{Motile sperm percentage}

The motile sperm percentage varied from extender to extender with significant $(\mathrm{P}<0.05)$ difference at $24 \mathrm{~h}, 48 \mathrm{~h}$ and $72 \mathrm{~h}$ of refrigeration. Addition of $1 \%$ honey in skim milk glutathione extender increased motile sperm percentage while addition of $1 \%$ honey in skim milk extender reduced it at $72 \mathrm{~h}$ of refrigeration (Table 5 and Figure 2). 


\section{Immotile sperm percentage}

The values of immotile sperm percentage differed significantly $(\mathrm{P}<0.05)$ from extender to extender at $24 \mathrm{~h}, 48 \mathrm{~h}$ and $72 \mathrm{~h}$ of refrigeration. Addition of $1 \%$ honey in skim milk glutathione extender reduced immotile sperm percentage in contrast addition of $2 \%$ honey in skim milk extender increased it at 72 $h$ of refrigeration (Table 6 and Figure 3).

\section{Discussion}

\section{Semen evaluation tests in Boer bucks}

The volume of neat semen ranged from 0.81 to $1.30 \mathrm{ml}$ having whitish yellow color. The mass activity was ++++ scale for all semen samples and sperm motility ranged from $91.66 \pm 1.12 \%$ to $96.66 \pm 1.42 \%$ and none of the samples has shown presence of any foreign body (Table 4 and Figure 1). Similar to the present study Kumbari (2017) recorded the semen volume ranged from $0.8 \pm 0.1$ to $1.2 \pm 0.2 \mathrm{~mL}$ while the color and mass activity were whitish - yellow and ++++ scale respectively in Boer bucks. However Florence et al., (2011) recorded the bucks pooled ejaculate average volume of $2.5 \mathrm{ml}$, creamy color and homogenous without flakes or clumps with average gross motility and sperm motility were assessed as +++ scale and $95 \%$ respectively.

Comparative effect of Boer buck sperm motility with $5 \mathrm{mM}$ glutathione and or $1 \%$ or $2 \%$ honey in skim milk based extenders preserved at refrigeration temperature at $0,24,48$ and $72 \mathrm{~h}$

\section{Motile sperm percentage}

The motile sperm percentage varied from extender to extender with significant $(\mathrm{P}<0.05)$ difference at $24 \mathrm{~h}, 48 \mathrm{~h}$ and $72 \mathrm{~h}$ of refrigeration. Addition of $1 \%$ honey in skim milk glutathione extender increased motile sperm percentage while addition of $1 \%$ honey in skim milk extender reduced it at $72 \mathrm{~h}$ of refrigeration (Table 5 and Figure 2). Kadaganchi (2017) also concluded that values for motile sperm percentage varied from dilutor to dilutor with significant difference at $0,24,48$ and 72 hours of preservation. The motile sperm percentage was recorded higher in SMFE and lower in $\operatorname{SMFH}(2 \%)$ GE at 0, 48 and 72 hours, however, $\operatorname{SMFH}(2 \%) \mathrm{E}$ dilutor shown less motile sperm percentage at 24 hours without any significant difference. The motile sperm percentage declined with increase in holding time in all extenders $(p<0.05)$. In contrast, Nancy (2018) stated that there was no effect of addition of antioxidants, almond and olive oil $(0.25 \%)$ in the semen extenders on motile sperm percentage.

\section{Immotile sperm percentage}

The values of immotile sperm percentage differed significantly $(\mathrm{P}<0.05)$ from extender to extender at $24 \mathrm{~h}, 48 \mathrm{~h}$ and $72 \mathrm{~h}$ of refrigeration. Addition of $1 \%$ honey in skim milk glutathione extender reduced immotile sperm percentage in contrast addition of $2 \%$ honey in skim milk extender increased it at 72 $\mathrm{h}$ of refrigeration (Table 6 and Figure 3). Similarly, Kadaganchi (2017) reported that, values for immotile sperm percentage varied from dilutor to dilutor with significant difference at 0,2448 and 72 hours of semen storage. The immotile sperm percentage improved $(\mathrm{p}<0.05)$ with increase in holding time in all extenders. As against, Nancy (2018) stated that, immotile sperm percentage increased $(\mathrm{P}<0.05)$ with increase in holding time in all extenders but there was no effect of addition of almond and olive oil $(0.25 \%)$ as antioxidants to reduce immotile sperm percentage. 
Table.1 Evaluation of semen for mass activity

\begin{tabular}{|c|c|}
\hline Mass activity & Score \\
\hline++++ & Rapid cloud formation \\
\hline+++ & Good cloud formation \\
\hline++ & Strong flow with some thickening \\
\hline+ & Poor flow \\
\hline
\end{tabular}

Table.2 Score chart for assessing sperm motility of the semen samples

\begin{tabular}{|l|c|}
\hline \multicolumn{1}{|c|}{ Sperm motility } & Percentage (\%) \\
\hline No movement & 0 \\
\hline No forward progression (only head movement) & $1-20$ \\
\hline $\begin{array}{l}\text { Slow forward sperm progression (usually with laboured head } \\
\text { movement) }\end{array}$ & $20-40$ \\
\hline Fast forward sperm progression & $40-60$ \\
\hline Faster forward sperm progression & $60-80$ \\
\hline Very fast forward movement & $80-100$ \\
\hline
\end{tabular}

Table.3 Group wise semen extenders with abbreviations

\begin{tabular}{|c|l|l|}
\hline Group No. & \multicolumn{1}{|c|}{ Semen Extenders } & Abbreviations \\
\hline I & Skimmed Milk Extender & SME \\
\hline II & Skimmed Milk - Glutathione Extender & SMGE \\
\hline III & Skimmed Milk - Glutathione - Honey (1\%) Extender & SMGH(1\%)E \\
\hline IV & Skimmed Milk - Glutathione - Honey (2\%) Extender & SMGH(2\%)E \\
\hline V & Skimmed Milk - Honey (1\%) Extender & SMH(1\%)E \\
\hline VI & Skimmed Milk - Honey (2\%) Extender & SMH(2\%)E \\
\hline
\end{tabular}

Table.4 Semen evaluation tests in Boer bucks

\begin{tabular}{|c|c|c|c|c|}
\hline $\begin{array}{l}\text { Buck } \\
\text { No. }\end{array}$ & $\begin{array}{c}\text { Volume (mL) (Mean } \\
\mathbf{\pm S E})\end{array}$ & Colour & $\begin{array}{c}\text { Mass } \\
\text { activity } \\
\text { +to }++++)\end{array}$ & $\begin{array}{c}\text { Sperm motility } \\
\text { (Mean } \pm \text { SE) }\end{array}$ \\
\hline $\mathbf{1}$ & $1.02 \pm 0.04$ & Whitish - yellow & ++++ & $94.16 \pm 1.48$ \\
\hline $\mathbf{2}$ & $0.82 \pm 0.04$ & Whitish - yellow & ++++ & $92.50 \pm 1.30$ \\
\hline $\mathbf{3}$ & $0.91 \pm 0.04$ & Whitish - yellow & ++++ & $93.33 \pm 1.42$ \\
\hline $\mathbf{4}$ & $0.81 \pm 0.02$ & Whitish - yellow & ++++ & $91.66 \pm 1.12$ \\
\hline $\mathbf{5}$ & $1.30 \pm 0.05$ & Whitish - yellow & ++++ & $96.66 \pm 1.42$ \\
\hline $\mathbf{6}$ & $1.21 \pm 0.04$ & Whitish - yellow & ++++ & $95.83 \pm 1.48$ \\
\hline
\end{tabular}


Table.5 Motile sperm percentage (Mean \pm SE) in sperm pellets diluted with skim milk based extenders at $0,24,48$ and $72 \mathrm{~h}$ of storage at refrigeration temperature

\begin{tabular}{|l|c|c|c|c|}
\hline Extenders & $\mathbf{0 ~ h}$ & $\mathbf{2 4} \mathbf{h}$ & $\mathbf{4 8} \mathbf{h}$ & $\mathbf{7 2} \mathbf{~ h}$ \\
\hline SME & $93.95^{\mathrm{aABC}} \pm 0.64$ & $87.66^{\mathrm{bAC}} \pm 0.60$ & $71.21^{\mathrm{cA}} \pm 0.76$ & $60.09^{\mathrm{dA}} \pm 0.99$ \\
\hline SMGE & $93.05^{\mathrm{aAC}} \pm 0.82$ & $81.70^{\mathrm{bB}} \pm 0.96$ & $64.86^{\mathrm{cB}} \pm 0.82$ & $56.05^{\mathrm{dAC}} \pm 1.01$ \\
\hline SMGH(1\%)E & $95.95^{\mathrm{aB}} \pm 0.51$ & $88.29^{\mathrm{bA}} \pm 0.35$ & $83.04^{\mathrm{cC}} \pm 0.39$ & $76.80^{\mathrm{dB}} \pm 0.65$ \\
\hline SMGH(2\%)E & $94.65^{\mathrm{aCB}} \pm 0.65$ & $87.85^{\mathrm{bAC}} \pm 0.35$ & $78.67^{\mathrm{cDE}} \pm 0.50$ & $74.34^{\mathrm{dB}} \pm 0.27$ \\
\hline SMH(1\%)E & $94.65^{\mathrm{aCB}} \pm 0.59$ & $88.40^{\mathrm{bA}} \pm 0.47$ & $75.35^{\mathrm{cE}} \pm 1.65$ & $59.82^{\mathrm{dA}} \pm 1.02$ \\
\hline SMH(2\%)E & $94.21^{\mathrm{aCB}} \pm 0.54$ & $85.62^{\mathrm{bC}} \pm 0.73$ & $76.77^{\mathrm{cE}} \pm 0.78$ & $52.51^{\mathrm{dC}} \pm 1.56$ \\
\hline
\end{tabular}

Note: SME: Skim Milk Extender, SMGE: Skim Milk Glutathione Extender, SMGH(1\%)E: Skim Milk

Glutathione Honey (1\%) Extender, SMGH(2\%)E: Skim Milk Glutathione Honey (2\%) Extender, SMH(1\%)E:

Skim Milk Honey (1\%) Extender, SMH(2\%)E: Skim Milk Honey (2\%) Extender

Means with different superscripts differ significantly at $\mathrm{P}<0.05$

abcd superscripts indicated the difference between time (columns) within extenders (rows)

${ }^{A B C D E}$ superscripts indicated the difference between extenders (rows) within time (columns)

Table.6 Immotile sperm percentage (Mean \pm SE) in sperm pellets diluted with skim milk based extenders at $0,24,48$ and $72 \mathrm{~h}$ of storage at refrigeration temperature

\begin{tabular}{|l|c|c|c|c|}
\hline Extenders & $\mathbf{0 ~ h}$ & $\mathbf{2 4} \mathbf{~ h}$ & $\mathbf{4 8} \mathbf{~}$ & $\mathbf{7 2} \mathbf{~ h}$ \\
\hline SME & $6.04^{\mathrm{aABC}} \pm 0.64$ & $12.33^{\mathrm{bAC}} \pm 0.60$ & $28.78^{\mathrm{cA}} \pm 0.76$ & $39.91^{\mathrm{dA}} \pm 0.99$ \\
\hline SMGE & $6.94^{\mathrm{aAC}} \pm 0.82$ & $18.30^{\mathrm{bB}} \pm 0.96$ & $35.13^{\mathrm{cB}} \pm 0.82$ & $43.94^{\mathrm{dAC}} \pm 1.01$ \\
\hline SMGH(1\%)E & $4.04^{\mathrm{a} B} \pm 0.51$ & $11.70^{\mathrm{bA}} \pm 0.35$ & $16.95^{\mathrm{CC}} \pm 0.39$ & $23.20^{\mathrm{dB}} \pm 0.65$ \\
\hline SMGH(2\%)E & $5.34^{\mathrm{aCB}} \pm 0.65$ & $12.15^{\mathrm{bAC}} \pm 0.35$ & $21.32^{\mathrm{CDE}} \pm 0.50$ & $25.65^{\mathrm{dB}} \pm 0.27$ \\
\hline SMH(1\%)E & $5.34^{\mathrm{aCB}} \pm 0.59$ & $11.60^{\mathrm{bA}} \pm 0.47$ & $24.64^{\mathrm{CE}} \pm 1.65$ & $40.17^{\mathrm{dA}} \pm 1.02$ \\
\hline SMH(2\%)E & $5.78^{\mathrm{aCB}} \pm 0.54$ & $14.37^{\mathrm{bC}} \pm 0.73$ & $23.22^{\mathrm{cE}} \pm 0.78$ & $47.48^{\mathrm{dC}} \pm 1.56$ \\
\hline
\end{tabular}

Note: SME: Skim Milk Extender, SMGE: Skim Milk Glutathione Extender, SMGH(1\%)E: Skim Milk Glutathione Honey (1\%) Extender, SMGH(2\%)E: Skim Milk Glutathione Honey (2\%) Extender, SMH(1\%)E: Skim Milk Honey (1\%) Extender, SMH(2\%)E: Skim Milk Honey (2\%) Extender Means with different superscripts differ significantly at $\mathrm{P}<0.05$ abcd superscripts indicated the difference between time (columns) within extenders (rows) ${ }^{A B C D E}$ superscripts indicated the difference between extenders (rows) within time (columns)

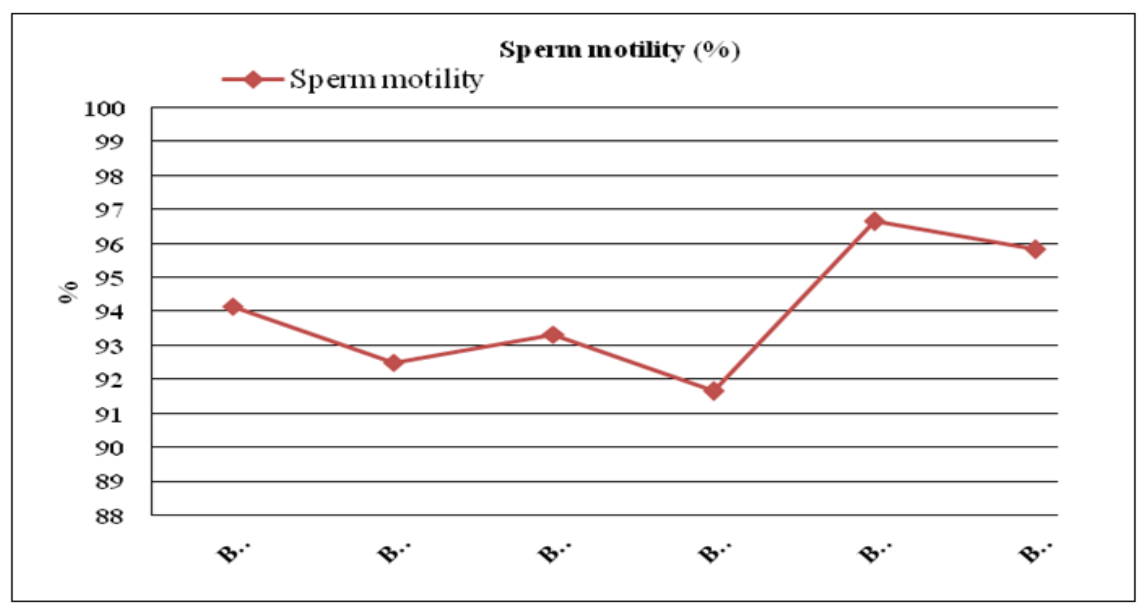

Figure.1 Semen evaluation tests in Boer bucks 


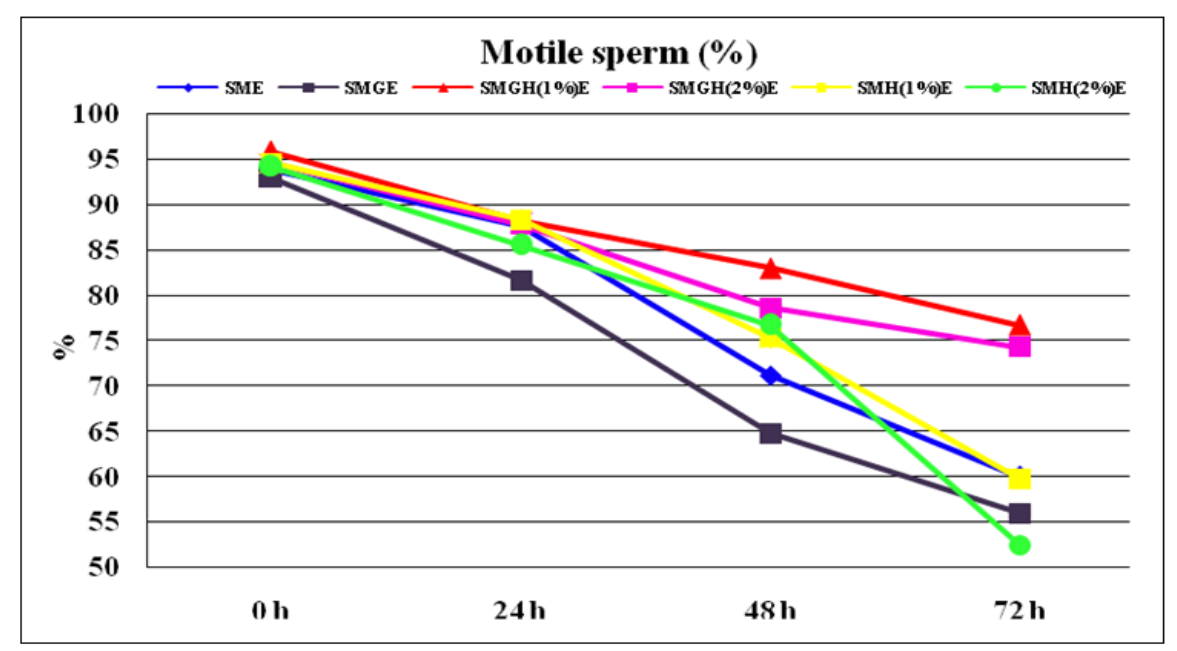

Figure. 2 Motile sperm percentage in sperm pellets diluted with skim milk based extenders at 0 , 24,48 and $72 \mathrm{~h}$ of storage at refrigeration temperature

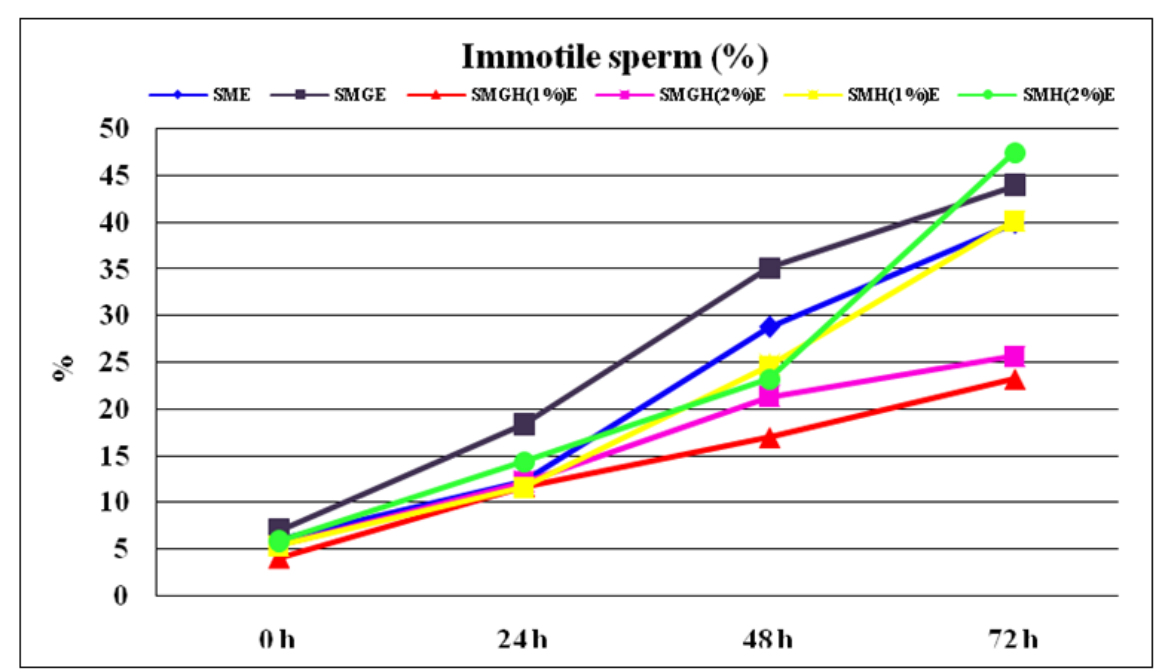

Figure.3 Immotile sperm percentage in sperm pellets diluted with skim milk based extenders at $0,24,48$ and $72 \mathrm{~h}$ of storage at refrigeration temperature

The results from the research study showed that both motile and immotile sperm percentages were differed significantly $(\mathrm{P}<0.05)$ from extender to extender at $24 \mathrm{~h}$, $48 \mathrm{~h}$ and $72 \mathrm{~h}$ of refrigeration. Based on the results concluded that supplementation of optimum concentration of glutathione $(5 \mathrm{mM})$ and honey (1\%) maintained better sperm motility upto 72 hours of storage and successful preservation of buck spermatozoa at refrigeration temperature. Hence Boer buck semen can be preserved effectively with
$\operatorname{SMGH}(1 \%) \mathrm{E}$, at refrigeration temperature upto 72 hours of storage.

\section{References}

Anand, M., Yadav, S. and Kumar, J., 2016. Kinematic response of Barbari and Sirohi buck spermatozoa to high egg yolk concentration in semen extender. J. Anim. Res., 6 (3): 493-497

Banday, M. N., Lone, F. A., Rasool, F., Rather, H. A. and Rather, M. A., 2017. 
Does natural honey act as an alternative to antibiotics in the semen extender for cryopreservation of crossbred ram semen. Iran. J. Vet. Res. Shiraz Univ., 18 (4): 258-263

Blokhuis, J., 1962. The artificial insemination in the goat. The semen of animals and artificial insemination. Panima publishing corporation, New Delhi.

El-Sheshtawy, R. I., El-Nattat, W. S., Sabra, H. A. and Ali, A. H., 2014. Effect of honey solution on semen preservability of local breeds of cattle bulls. World App. Sci. J., 32 (10): 2076-2078

Florence, O. O., Deborah, A. A. and Mathew, O. O., 2011. Evaluation of sperm motility and viability in honey-included egg yolk based extenders. Global Veterinaria, 7 (1): 19-21

Hassan, S. M., Andrabi, A., Mehmood, M., Anwar, M. and Fatahullah, K., 2016. In vitro viability and longevity of cooled Beetal buck spermatozoa extended in skimmed milk and tris-citric acid based extenders. Small Rum. Res., 143: 61-66

Kadaganchi, A., 2017. Evaluation of semen preserved at refrigeration temperature by computer assisted semen analysis (CASA) of NARI Suwarna strain of sheep. M.V.Sc. Thesis, KVAFSU, Bidar, Karnataka.

Kumbari, M., 2017. Evaluation of Boer buck's semen preserved at refrigeration temperature by computer assisted semen analysis (CASA). M.V.Sc. Thesis, KVAFSU, Bidar, Karnataka.

Loskutoff, N. M. and Crichton, E. G., 2001. Standard operating procedures for genome resource banking. The bill and
Bernience-Grewcock center for conservation and research Omaha's zoo, pp: $1-16$

Nancy, J., 2018. Supplementation of olive and almond oil in extenders for preservation of semen in NARI Suwarna strain of sheep. M.V.Sc. Thesis, KVAFSU, Bidar, Karnataka.

Noei, R., Zhandi, M., Shakeri, M., Towhidi, A., Sharafi, M., Emamverdi, M. and Khodaei, M. M., 2015. Protective role of glutathione in buck semen cryopreservation. Iran. J. Vet. Res., 16 (3): 298-300

Rimon, A., Jha, P. K., Mansur, A. A., Islam, M. M., Juyena, N. S. and Bari, F. Y., 2017. Quality of chilled indigenous ram semen using multi-species skim milk based extenders. Int. J. Anim. Vet. Sci., 11 (1): 23-28

Sarangi, A., Singh, P., Virmani, M., Yadav, A. S., Sahu, S., Ajithakumar, H. M., Kumari, A. and Rath, A. P., 2017. Effect of antioxidants supplementation on the quality of Beetal buck semen stored at $4^{\circ} \mathrm{C}$. Vet. World, 10 (10): $1184-1188$

Yimer, N., Muhammad, N., Sarsaifi, K., Rosnina, Y., Wahid, H., Khumran, A. M. and Kaka, A., 2015. Effect of honey supplementation into Tris extender on cryopreservation of bull spermatozoa. Mal. J. Anim. Sci., 18 (2): 47-54

Zoheir, K. M. A., Harisa, G. I., Abo-Salem, O. M. and Sheikh, F. A. S. F., 2015. Honey bee is a potential antioxidant against cyclophosphamide induced genotoxicity in albino male mice. Pak. J. Pharm. Sci., 28 (3): 973-981

\section{How to cite this article:}

Suresh Arakeri, M. K. Tandle, M. D. Suranagi, Vinay Tikare, R. G. Bijurkar, Jagannath Rao and Shrikant Kulkarni. 2020. Evaluation of Sperm Motility with Glutathione and Honey in Skim Milk based Extenders by CASA in Boer Buck. Int.J.Curr.Microbiol.App.Sci. 9(05): 3420-3427. doi: https://doi.org/10.20546/ijcmas.2020.905.406 